LIAMES, Campinas, SP, v. 20, 1-32, e020009, 2020

\title{
Repensando los sufijos direccionales del aimara y otras lenguas nativas de Sudamérica
}

\author{
Erik Cajavilca Veramendi \\ Universidad Nacional Mayor de San Marcos, Perú \\ https://orcid.org/0000-0003-0274-9616
}

\author{
Roslyn Cajas Ascanoa \\ Universidad de San Martín de Porres, Perú \\ https://orcid.org/0000-0002-3066-3265
}

\begin{abstract}
Based on Talmy's (2007) theory, about semantic categories in motion events, the concept of directional suffixes has been delimited in twenty-six Andean and Amazon languages. Therefore, directional suffixes have been determined to be morphemes that encode the semantic category "path" in motion verbs. Starting from Aymara, which registers a wide variety of directional suffixes, it was found that various languages of the region also use these suffixes embedded in the pre-inflectional boxes of the verbal structure. Their presence in a language does not depend on geographic factors, they are found even in the lowlands of Vaupés (Wanano) and Purús (Jarawara). While in modern Quechua and Chipaya, despite being highland languages such as Aymara, directional suffixes are not maintained and tend to expire. On the other hand, the comparative examination of the presence of directional suffixes, in the twenty-six languages studied, indicates how they have evolved; in one case, how they become suffixes, and how they become extinct and leave a trace in aspectual suffixes or as a fossilized segment in a root.
\end{abstract}

KEYWORDS: Directional suffixes; Aymara; Motion verb; Motion path; Amazon languages.

RESUMEN: Com base na teoria de Talmy (2007), sobre categorias semânticas em eventos de movimento, o conceito de sufixos direcionais foi delimitado em vinte e seis línguas andinas e amazônicas. Portanto, verificouse que os sufixos direcionais são morfemas que codificam a categoria semântica de "trajetória" em verbos de movimento. A partir da língua aimará, que registra uma grande variedade de sufixos direcionais, verificou-se que várias línguas da região também usam esses sufixos incorporados nas caixas pré-flexionadas da estrutura verbal. A presença deles em uma língua não depende de fatores geográficos, pois são encontrados até nas planícies do Vaupés (Wanano) e Purus (Jarawara); enquanto no moderno quíchua e chipaya, apesar de serem línguas das terras altas, como o aimará, os sufixos direcionais não são mantidos e tendem a expirar. Por outro lado, o exame comparativo da presença de sufixos direcionais, entre as vinte e seis línguas estudadas, indica como eles evoluíram ao longo do tempo; em um caso, como eles se tornam sufixos e, em outro, como eles se extinguem e deixam vestígios em sufixos de aspecto ou como um segmento fossilizado em uma raiz.

PalaVRas-chaVe: Sufixos direcionais; Aimará; Verbos de movimento; Trajetória de movimento; Línguas da Amazônia. 


\section{CAJAVILCA VERAMENDI \& CAJAS ASCANOA - REPENSANDO LOS...}

\section{Introducción}

La lengua aimara, una lengua aglutinante de los Andes peruanos y bolivianos, hace uso de una amplia gama de morfemas que expresan la dirección del movimiento y que se adjuntan a la derecha de la raíz verbal. La diversidad de estos sufijos direccionales constituye un rico inventario que no ha sido encontrado en otras lenguas cercanas por lo que se considera que es un sello distintivo del aimara y un rasgo destacado en la tipología lingüística. Esto ha motivado un tratamiento especial de dichos sufijos en la literatura aimarista, sin embargo, este tratamiento ha sido principalmente descriptivo, abordando la posición que ocupa en la estructura verbal y su semántica individual (véase, por ejemplo, Huayhua 2001; Hardman 2000, 2001; Marcapaillo 2009; Coler 2014; Gonzalo 2011).

En este artículo, abordamos los sufijos direccionales dentro de un marco comparativo y desde la perspectiva semántica de los eventos de movimiento de Talmy (2007). Tomando en cuenta la categoría semántica de la trayectoria y otras características morfológicas descritas en la sección 3, indagaremos qué otras lenguas de la región presentan sufijos verbales que expresan la trayectoria del movimiento. En caso contrario, veremos si las lenguas usan, más bien, otras estrategias no sufijantes para marcar la trayectoria del movimiento.

De esta manera, nuestro objetivo primario se centra en describir la ocurrencia de sufijos direccionales del tipo aimara en otras lenguas de la región ${ }^{1} \mathrm{y}$, como segundo objetivo, descubrir el comportamiento estructural y la productividad de los sufijos direccionales en las lenguas que los emplean. Empezaremos, entonces, por describir el evento de movimiento y sus categorías semánticas. Luego determinaremos las condiciones que debe reunir un elemento para ser llamado sufijo direccional (SD) en este artículo. Así, pasamos a analizar descriptivamente los SD en varias lenguas nativas de Sudamérica, teniendo como punto focal al aimara de los Andes. Cuestiones más profundas sobre la semántica extendida, connotaciones o sobre su función derivativa denominal de los SD no serán analizadas, sino solo mencionadas someramente.

\section{Conceptos claves: el evento de movimiento}

En principio, un evento de movimiento debe informar sobre el objeto movido, la trayectoria del movimiento y la meta. El siguiente esquema describe este evento:

${ }^{1}$ En total, hemos examinado 26 lenguas nativas sudamericanas, incluyendo tres lenguas quechua que pertenecen a ramas separadas; por lo tanto, se las ha contabilizado por separado. 


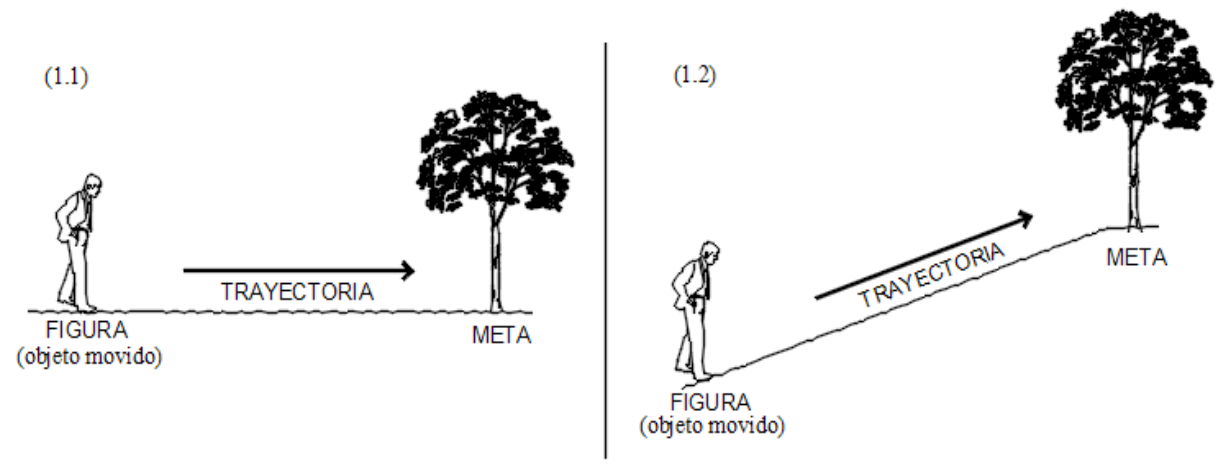

Imagen 1: Eventos de movimiento

Prototípicamente, tanto el objeto movido como la meta son unidades léxicas independientes no asociadas con el verbo; mientras que la trayectoria puede estar especificada en el verbo mismo o en un elemento asociado con el verbo (afijo, clítico, partícula, etc.). Por ejemplo, en el evento 1.1 de la imagen, la oración el hombre va hacia el árbol informa sobre el objeto movido (hombre), la meta (árbol) y la trayectoria, la cual está expresada inherentemente en el verbo $i r$. De la misma forma, en la oración el hombre sube hacia el árbol del evento 1.2, la trayectoria está expresada en el verbo subir. En la práctica, el evento de movimiento involucra otros valores adicionales, como es la manera del movimiento - muy común en las lenguas-, el origen, el recipiente, el lugar, el agente (cf. Zheng y Goldin-Meadow 2002: 149). Asimismo, las lenguas emplean otros recursos sintácticos y morfológicos no prototípicos para codificar el evento de movimiento; por ejemplo, en la oración vino ayer, aunque no se enuncia la meta en una unidad léxica aparte, esta está contenida en el verbo deíctico venir.

Partiendo del hecho de que el verbo es el elemento nuclear de todo evento de movimiento, las lenguas se reservan el derecho de qué enunciar en la oración. En algunos casos, se informa el objeto movido (en adelante «figura»), la trayectoria y la meta; en otros casos, solo la figura y la trayectoria, o solo la figura y la manera, entre otras combinaciones. A continuación, abordaremos la forma cómo se indica la trayectoria, la manera y la meta en la oración poniendo énfasis en el verbo de movimiento. ${ }^{2}$

a) La trayectoria constituye el camino recorrido - ya sea en un espacio bidimensional o tridimensional - por la figura al moverse desde un punto de origen hasta una meta $\mathrm{o}$, en palabras de Talmy (2007: 70), la figura se mueve con respecto a un objeto de referencia (ground). La indicación de la trayectoria se realiza de dos formas: enmarcada en el verbo o enmarcada en el satélite. En el primer caso, la trayectoria se especifica semánticamente en la misma raíz verbal, tal como los verbos españoles subir, bajar; mientras que, en el segundo, la trayectoria se especifica en un elemento asociado con el verbo que puede ser

${ }^{2}$ Verbos de movimiento: incluye a verbos de desplazamiento o locomoción (intransitivos) como ir, subir, correr, caminar, nadar, volar, surcar, y verbos de transportación (transitivos) como llevar, colocar, cargar, subir (algo). 
ligado o no ligado, tal como un afijo, clítico o partícula. Téngase en cuenta que la trayectoria implica solo la línea del recorrido, el cual establece la dirección del movimiento; es decir, no necesariamente debe marcar todo el recorrido desde el origen hasta la meta, basta con un valor en su mínima expresión tal como sucede con los verbos deícticos del español ir y venir (cf. Tanghe 2016: 53). En la oración se fue, la trayectoria es indicada apenas en el verbo $i r$, en donde la figura tácita se aleja del centro deíctico, pero no se informa en qué dirección. ${ }^{3}$ En efecto, el verbo deíctico ir tiene la facultad de informar sobre el origen del movimiento, mientras que el verbo deíctico venir informa sobre la meta del movimiento. Tal vez no queda claro la constitución de la trayectoria en estos tipos de verbos, no obstante, seguiremos la consideración expresada por otros investigadores, por lo tanto, consideraremos a los verbos o satélites que expresen «ir» y «venir» como elementos de trayectoria. Debemos precisar que la trayectoria es un componente obligatorio del evento de movimiento (Slobin 2004: 238), por lo tanto, si la trayectoria no está explícito en el verbo o en un satélite, esta se deduce a partir del origen o de la meta.

b) La manera es la forma como la figura se mueve y es una categoría que concierne diversos matices: el tipo de locomoción, tipo de transporte, la velocidad, la cantidad, la intensidad, entre otros. Al igual que la trayectoria, la indicación de la manera se realiza de dos formas: enmarcada en el verbo o enmarcada en el satélite. En el primer caso, la manera se especifica semánticamente en la misma raíz verbal, tal como los verbos españoles caminar, correr o el aimara achu 'llevar en la boca'; mientras que, en el segundo, la manera se especifica en un elemento asociado con el verbo que puede ser ligado o no ligado; por ejemplo, en español se emplea el gerundio (corriendo) para especificar la manera pospuesto al verbo de trayectoria: entró corriendo. En algunos casos, el evento de movimiento se compone de la figura, la manera y la meta; es decir, prescinde de una expresión de trayectoria explícita, ya que la meta está especificando hacia donde se dirige la figura (véase la definición de meta). Las oraciones que especifican solo la figura y la manera, como en (1), se emplean para informar alguna habilidad o característica natural; no es, pues, una forma prototípica de expresar el evento de movimiento sin la trayectoria, la meta y el origen:

\section{(1) El delfín nada \\ El canguro salta \\ El anciano camina lento}

c) La meta es el punto donde termina la trayectoria. Esta categoría se especifica en elementos léxicos independientes y cuyo contenido es esencialmente nominal. Salvo en los verbos deícticos, en que el origen y la meta es el lugar del acto de habla, la información de la meta se construye de diversas formas, ya sea mediante un adjunto, adverbio,

${ }^{3}$ Debido a que el verbo ir no informa estrictamente la dirección, ni la meta se considera un verbo de movimiento atélico. Por otro lado, Chen y Guo (2009: 1755) clasifican a los verbos ir y venir separados de los verbos de trayectoria típicos: verbos de trayectoria no deícticos (subir, bajar) versus verbos de trayectoria deícticos (ir, venir). Asimismo, el verbo islandés fara 'ir' es considerado un verbo neutral de movimiento, es decir, no indica trayectoria ni manera (cf. Croft et al. 2010: 213). 
complemento locativo, frase preposicional, frase adverbial. La enunciación de la meta es el recurso más productivo que emplean las lenguas en los eventos de movimiento. Por ejemplo, en los siguientes enunciados del español, la meta (negrita) se indica tanto en una oración con verbo de trayectoria como en otra, con verbo de manera.

(2) Verbo de trayectoria $i r$ :

Iré al cine

(3) Verbo de manera arrastrarse:

El hombre se arrastró a la orilla

La lengua española también hace uso de adverbios direccionales semánticamente similares a las partículas del inglés down, into, out que se emplean junto a verbos de manera para construir eventos de movimiento, tal como en la oración I ran out of the house. Sin embargo, los adverbios direccionales del español — abajo, arriba, adentro, afuera, entre otros- se estructuran de forma diferente a las partículas del inglés, pues estas están asociadas morfológicamente al verbo; mientras que los adverbios del español forman parte de otro sintagma en el evento de movimiento. Por ejemplo, en la oración el ciervo corrió hacia abajo, el adverbio direccional abajo forma parte del sintagma preposicional hacia abajo, que funciona como un complemento circunstancial de lugar (en español, un adverbio direccional se nominaliza cuando va precedido de una preposición); por lo tanto, el adverbio abajo realiza el papel de meta, aunque semánticamente exprese la trayectoria del movimiento. En suma, todas las lenguas, en mayor o menor medida, tienen verbos de trayectoria y de manera inherente en su lexicón, pero cada una de ellas emplea distintos recursos para completar los componentes del evento de movimiento.

d) Otras categorías semánticas. La lista que proporcionan Zheng y Goldin-Meadow (2002: 149) consta de nueve categorías semánticas del evento de movimiento: movimiento, trayectoria, manera, figura, origen, meta, recipiente, lugar y agente. Las lenguas deben especificar mínimamente — aparte de la categoría de movimiento que resulta obviados categorías del grupo, por ejemplo, figura y trayectoria; y como máximo, las nueve categorías. Ahora bien, las lenguas se reservan el derecho de especificar minuciosamente el evento de movimiento o simplemente dejarlo impreciso; ellas eligen qué y cuántas de estas categorías informar. Veamos algunos ejemplos de la cantidad de información en eventos de movimiento:

(4) El auto se movió

[figura], [movimiento]

El vaso se cayó

[figura], [movimiento], [trayectoria]

Se fue

[figura tácita], [movimiento], [trayectoria], [origen]

Subió a su dormitorio [figura tácita], [movimiento], [trayectoria], [meta]

La moneda rodó hasta el jardín ${ }^{4}$ [figura], [movimiento], [manera], [meta]

Me voy allá [figura tácita], [movimiento], [trayectoria], [origen], [meta]

${ }^{4}$ Como declaramos previamente, en este enunciado, la trayectoria no está ausente en el evento de movimiento, sino se deduce a partir de la meta (jardín). 
Se da también la redundancia de categorías, por ejemplo, al indicar dos veces la trayectoria:

(5) Ruso (Croft et al. 2010: 215)

$\begin{array}{lll}\text { Ptičkata ot-letya } & \text { ot } & \text { gnezdoto } \\ \text { pájaro.el fuera-volar.PRF.AOR } & \text { fuera.de } & \text { nido.el }\end{array}$

'El pájaro voló fuera del nido'

Ahora bien, hay lenguas que explotan sus recursos verbales para codificar dichas categorías semánticas. Esta es generalmente una habilidad de las lenguas polisintéticas, en donde sus raíces verbales pueden codificar más de dos categorías o, en todo caso, emplean elementos satélites ligados que reemplazan a unidades lexicales independientes; por ejemplo, en (6) obsérvese que el verbo de movimiento íoove expresa [trayectoria], [manera] y [lugar] en una sola raíz de la lengua bora, mientras que en español se debe utilizar hasta siete palabras.

(6) Bora (Thiesen y Thiesen 1998)

ioove 'ir río abajo llevado por la corriente'

paaro 'poner abajo algo que se lleva cargado'

naúcú 'meter un palo en un hueco buscando un animal'

mohña 'caminar sigilosamente para sorprender'

El asháninka reporta también interesantes verbos de movimiento que codifican más de dos categorías semánticas:

(7) Asháninka (Kindberg 1980)

avisaa- 'poner bebé en hamaca'

okia-/kia- 'pasar o entrar a través de un hueco'

omarota $^{5}$ 'llevar el viento las cosas'

La descripción tipológica de Talmy (2007) se basó en el binomio verbo/satélite con respecto al componente de trayectoria del evento de movimiento; así las lenguas se van a dividir en lenguas que codifican inherentemente la trayectoria en el verbo de movimiento y lenguas que codifican la trayectoria en un elemento satélite, dependiendo de si para una lengua es más determinante especificar la trayectoria o la manera en la raíz verbal que funciona como núcleo sintagmático.

\section{3. ¿Qué son los sufijos direccionales de los VM?}

Los sufijos direccionales (SD) son elementos satélites que se unen a verbos de movimiento (VM) para indicar la trayectoria, precisamente porque dichos verbos carecen

${ }^{5}$ Este verbo lleva fosilizado, evidentemente, el sufijo modal -ta 'inminente' reportado por Kindberg (1980) y que indica el adverbio 'ahorita'. En Snell (2011), clasificado también como sufijo modal, indica ir hacia un lugar por un corto tiempo para luego regresar. Este sufijo es copia del sufijo aimara - $t$ 'a 'instantáneo', aunque no podemos afirmar quién prestó a quién. 
inherentemente de la categoría semántica de trayectoria, por lo tanto, son generalmente verbos de manera. En teoría, los verbos de trayectoria — como los del español subir, bajar, entrar, salir - no necesitan estos tipos de sufijos; sin embargo, las estructuras lingüísticas a veces no son tan predecibles, por lo que se dan casos de redundancia en que un SD se emplea a pesar de que otro satélite ya está marcando la trayectoria en el evento de movimiento o, de otro modo, la trayectoria se especifica tanto en un verbo de trayectoria como en un $\mathrm{SD}$; véase (5) y los ejemplos siguientes:

(8) Wanano (Stenzel 2004: 284)

$\begin{array}{lll}\text { kũ-ko-ro ti } & \text { bãhã-ta'a-chu } & \text { thH'o-roka-a } \\ \text { uno-f-sG 3PL.POS } & \text { ir.cuesta.arriba-venir-SW.REF } & \text { oír-DIST-ASER.PRF } \\ \text { 'una mujer los oyó acercarse' } & \end{array}$

(9) Wanano (Stenzel 2004: 289)
ti yoa-ri-pa
dũdũ-sito-ta-a
ANA ser.largo-NML-tiempo
perseguir-ir.alrededor-venir-ASER.PRF

'(Los perros) persiguieron aquí y allá durante mucho tiempo'

(10) Hãtxa kuĩ (Kaxinawá 2014: 226)

$\begin{array}{lllllllll}\text { haska } & \text { kai } & \text { ni } & \text { kai } & \text { rã, } & \text { unu } & \text { había } & \text { haw̃̃ } & \text { at } f i \\ \text { así } & \text { ir } & \text { REM } & \text { ir } & \text { FOC.1 } & \text { allí } & \text { ese } & \text { 3.GEN } & \text { tía }\end{array}$

'así que fue directo a su tía'

En el quechua se reporta casos en que los SD se unen a verbos de trayectoria. Los siguientes ejemplos corresponden al quechua del Huallaga: el SD $-y k u$ 'adentro' sufijado al verbo de trayectoria yayku- 'entrar' (Weber 1996: 180); el SD -rpu 'abajo' sufijado a los verbos de trayectoria ura- 'bajar' y yaqa- 'caer' (ibíd.: 181); el SD -rku 'arriba' sufijado al verbo hoqa- 'levantar' (Weber et al. 1998: 246). No obstante, la declaración inicial de la incidencia del SD en el tipo de verbo está inspirada en el aimara principalmente, como se verá en la sección 4.3; por lo tanto, creemos que los SD son más productivos con verbos de manera que con otro tipo de verbo. ${ }^{6}$

Ahora bien, puesto que todas las lenguas tienen verbos de manera, el empleo de SD para expresar la trayectoria no es, sin embargo, un recurso universal. Hay lenguas, como el inglés, que emplean partículas direccionales pospuestas al verbo (11), y otras, como el español, que dejan sin explicitar la trayectoria, ya que esta está implícita en la meta (12):

(11) Verbo de manera run:

He ran into the cave

(12) Verbo de manera arrastrarse:

El hombre se arrastró a la orilla

${ }^{6}$ Otro verbo de movimiento que no es ni de trayectoria ni de manera es el verbo neutral moverse. La lengua jarawara, por ejemplo, presenta el verbo $k a$ - 'estar en movimiento', el cual admite la sufijación de SD, véase la oración (39). 
En las gramáticas descriptivas, encontramos dos tipos de designaciones para los SD que tienen que ver con su semántica y su ordenamiento morfológico. Respecto a su semántica, puesto que los SD otorgan significado espacial al núcleo verbal, son llamados «sufijos adverbiales» (cf. Faust y Loos 2002: 130; Mihas 2010: 104). Por otro lado, puesto que se posicionan adyacentes a la raíz verbal, antes de los morfemas flexivos, se les ha considerado «sufijos derivativos» (cf. Hardman 2001: 73; Fleck 2003: 364; Zariquiey 2011: 395; Cerrón-Palomino 2006: 155, 161). Los SD no son, pues, rígidamente asignados como una u otra clase, sin embargo, dichas características semánticas y morfológicas nos dan alguna aproximación a su estatus morfológico. Por ejemplo, Duff-Tripp (1997: 83) los agrupa dentro de la clase denominada «sufijos de aspecto, tiempo y espacio», los cuales se ubican después de los sufijos derivativos y los de cambio de valencia.

En interés de este artículo, hacemos una distinción con los sufijos direccionales nominales. Estos son sufijos que se unen exclusivamente a elementos nominales para indicar la meta; por lo tanto, no los vamos a considerar como SD. Por ejemplo:

(13) Bora (Thiesen 1996: 87)

o péé téhullé-vu
$1 \mathrm{SG}$ ir allá-DIR (destino)
'Me voy allá'

(14) Bora (Thiesen 1996: 87)

ávyéjuube tsáá i-hjyá-tu
jefe venir 3Pos-casa-DIR
'El jefe viene de su casa'

Los sufijos direccionales nominales se comportan como los morfemas de caso locativo-direccional; obsérvese que en (13) y (14) los sufijos direccionales - vu y -tu funcionan como alativo y ablativo, respectivamente. En los eventos de movimiento, son sufijos que validan la meta o el origen con el verbo de movimiento.

Por otro lado, sufijos verbales que indican la localización de la figura como, por ejemplo, el sufijo -fara '(en) espacio despejado' del jarawara (cf. Dixon 2004: 144) tampoco serán considerados SD.

Vamos a considerar cuatro condiciones para la identificación de los SD:

1. Sufijos que se unen a verbos. Prototípicamente a VM de manera.

2. Sufijos que especifican la trayectoria o dirección realizada por la figura con respecto a la meta.

3. Son considerados SD aquellos que expresan significado espacial-direccional en primer lugar, antes que los significados aspectuales, modales o metafóricos.

4. Sufijos añadidos cerca de la raíz verbal, ubicándose antes de los sufijos flexivos u obligatorios. $^{7}$

${ }^{7}$ Esta no es una condición necesariamente rigurosa; por lo tanto, un SD podría posicionarse en las casillas terminales de los morfemas verbales. 
Todas estas condiciones deben cumplirse para ser considerado un sufijo direccional en este artículo. La lengua por excelencia que emplea los elementos que cumplen con estas condiciones es el aimara de los Andes. En adelante, tomaremos como punto de partida la tipología de SD del aimara y examinaremos su presencia en otras lenguas nativas. Ahora bien, Huayhua (2001) llama a los sufijos direccionales «deícticos verbales», sin embargo, esta es una denominación dudosa. Según su gramática, excepto el cis-translocativo - $n i$, no hay explicaciones ni ejemplos que ilustren el valor deíctico de los SD que él enumera. Además, ninguno de los autores revisados en este artículo llama «deícticos verbales» a los SD. A continuación, haremos un análisis descriptivo de estos elementos en el aimara.

\section{Los sufijos direccionales de las lenguas aimaraicas}

La familia lingüística aimaraica está conformada por la lengua aimara, jaqaru y cauqui. Actualmente, el aimara es la lengua representativa de la familia, ya que es hablada por más de dos millones de personas en el Altiplano andino del Perú, Bolivia y Chile. El aimara es una lengua aglutinante, sufijante y tiene un orden básico SOV (cf. Adelaar 2004). Contrariamente, las lenguas jaqaru y cauqui están en peligro de extinción y se asientan en comunidades rurales apartadas de la sierra limeña (cf. Hardman 2001).

Tomaremos como base el libro de gramática aimara de Huayhua (2001) y, en segundo lugar, la obra de Hardman (2001). Hardman clasifica dichos sufijos según el ordenamiento lineal en la palabra, mientras que Huayhua ${ }^{8}$ los clasifica según su semántica, una apreciación que tomaremos en cuenta.

\subsection{Semántica de los SD en el aimara}

Huayhua (2001) reporta 19 sufijos direccionales que clasifica en dos grupos generales: direccionales propiamente y ubicativos. Los primeros se dividen a su vez en horizontales, verticales, rotativos, divergentes y convergentes; todos estos cumplen las cuatro condiciones antes señaladas. En principio, los SD del aimara expresan la trayectoria, no obstante, el significado se extiende también a la categoría del aspecto, por ejemplo, el sufijo -xaru no solo indica dirección horizontal desde un punto fijo, sino también comienzo de la acción verbal. Cabe indicar que, cuando se usa con verbos de movimiento, denota la trayectoria del movimiento, es decir, no cambia el significado central del verbo; mientras que cuando se usa con verbos de no movimiento, el significado central del verbo se ve afectado, en todo caso, le confiere un valor aspectual. Por otro lado, algunos sufijos son capaces de verbalizar raíces nominales, otorgando sentidos diversos que no necesariamente se predicen a partir de su significado espacial. Aquí solo nos vamos ocupar del sentido direccional de los SD.

\subsection{Morfología de los SD en el aimara}

Los SD del aimara se unen de forma contigua a las raíces verbales; es decir, tienden a ubicarse en las casillas de los morfemas derivativos. En el aimara descrito por Huayhua

\footnotetext{
${ }^{8}$ El aimara descrito por Huayhua (2001) es, generalmente, el de Puno, distrito de Conima; mientras que el aimara descrito por Hardman (2001) es, generalmente, el de La Paz.
} 
(2001), no se descarta que puedan alternar su posición con algunos sufijos independientes, pero lo que sí deja claro el autor es que van antes de los sufijos flexivos.

Por lo tanto, Huayhua los etiqueta como sufijos derivativos en su inventario de afijos (cf. Huayhua 2001: 112). La alineación es como sigue, en donde las casillas a partir de NU hacia la derecha son considerados sufijos flexivos:

\section{V-(DE-ADV/SD-ASP)-SI-NU-MOD-T-P ${ }^{9}$}

Por otro lado, Hardman (2001), como ya mencionamos, clasifica a los SD según su incidencia en la estructura del complemento. Hardman denomina clase I a los sufijos que afectan solo a la raíz o raíz compleja y clase II a los sufijos que afectan a los complementos del verbo resultante y que además ocurren con temas verbales. Los SD de Huayhua pertenecen en su mayoría a la clase I de Hardman. A grandes rasgos, coincide con Huayhua en que los SD se ubican en los primeros lugares de la hilera morfémica, alternando con los sufijos aspectuales. Los significados son casi los mismos entre los dos autores, aunque hay algunas pocas excepciones. En Hardman (2001), se hace más notoria la dispersión de los sentidos derivados que no pueden ser fácilmente predecibles cuando se unen a verbos de no movimiento y a nombres; estas cuestiones se las dejamos a los expertos gramáticos aimaristas.

\subsection{Los verbos de movimiento que emplean SD en el aimara}

La característica más importante de los $\mathrm{SD}$, que interesa a nuestros propósitos, tiene que ver con su categoría semántica de trayectoria y su incidencia en los VM. Veamos los tipos de verbos que reciben la sufijación de SD según Huayhua (2001: 177-195) en el Cuadro 1 y según Hardman (2001: 76-88) en el Cuadro 2. Téngase en cuenta que registramos solo la glosa en español que corresponde a cada verbo y nombre aimara.

${ }^{9}$ V: raíz verbal. Los siguientes son sufijos: DE: derivativo; ADV: adverbio; SD: sufijo direccional; ASP: aspecto; SI: sufijo independiente; NU: número; MOD: modo; T: tiempo; P: persona. Huayhua (2001) considera al grupo (DE-ADV-ASP) como sufijos derivativos en general, es decir, ocupan una sola casilla morfémica. Los sufijos direccionales son aquí sufijos adverbiales ADV. 
LIAMES 20

Cuadro 1: Verbos y nombres que reciben la sufijación de los SD en aimara (Huayhua 2001)

\begin{tabular}{|c|c|c|c|}
\hline SD & Verbos de movimiento & Otros verbos & Nominales \\
\hline -xasi 'preventivo' & $\begin{array}{l}\text { llevar en brazos a un niño; llevar recipiente } \\
\text { plano }\end{array}$ & sentarse & \\
\hline -xaru 'dinámico' & $\begin{array}{l}\text { llevar en la boca; llevar en el regazo; llevar } \\
\text { en mantel }\end{array}$ & cocinar, pararse & \\
\hline -t’a 'instantáneo' & $\begin{array}{l}\text { llevar objetos largos al hombro; llevar } \\
\text { recipiente plano; llevar objeto alargado en la } \\
\text { mano }\end{array}$ & dormir, morir, comer & piedra, rojo \\
\hline$-n i$ 'cisloc, transloc' & $\begin{array}{l}\text { llevar entre dos o más objeto en procesión; } \\
\text { cargar en llama }\end{array}$ & dormir, jugar & rojo \\
\hline -qa 'descendente' & $\begin{array}{l}\text { ir en tumulto, fluir agua; desplazamiento } \\
\text { de agua y barro; correr en grupo; hacinar } \\
\text { horizontalmente }\end{array}$ & tapar con algo pesado & \\
\hline -ranta 'descendente' & $\begin{array}{l}\text { empujar; llevar en recipiente cosas menudas; } \\
\text { llevar un bulto en la espalda }\end{array}$ & & \\
\hline -nta 'introductivo' & $\begin{array}{l}\text { empujar; llevar objetos livianos; llevar un } \\
\text { bulto en la espalda; llevar empujando con palo } \\
\text { o palanquear }\end{array}$ & & \\
\hline $\begin{array}{l}\text {-ta 'incoativo, } \\
\text { ascendente' }\end{array}$ & $\begin{array}{l}\text { llevar un objeto tomado de las asas; llevar } \\
\text { objeto alargado en la mano; ir en tumulto }\end{array}$ & & rojo, verde \\
\hline -kata 'ascendente' & $\begin{array}{l}\text { llevar en el regazo; correr, volar; llevar niño } \\
\text { en brazos }\end{array}$ & & \\
\hline -su 'extractivo' & $\begin{array}{l}\text { ir en tumulto; arrear ganado; correr, volar; } \\
\text { salir, trepar }\end{array}$ & & \\
\hline -kipa 'rotativo' & $\begin{array}{l}\text { llevar de la mano o con soga; llevar en un } \\
\text { puñado; llevar objetos largos al hombro }\end{array}$ & & amarillo \\
\hline -naqa 'rotativo' & llevar en el fondo; empujar & & \\
\hline -tata 'divergente' & $\begin{array}{l}\text { llevar objetos largos al hombro; llevar con los } \\
\text { dos brazos; desplazamiento de agua y barro }\end{array}$ & & \\
\hline -wacha 'divergente' & $\begin{array}{l}\text { empujar; llevar con la palma de la mano; } \\
\text { llevar empujando con palo }\end{array}$ & & \\
\hline -thapi 'convergente' & $\begin{array}{l}\text { llevar objetos largos al hombro; llevar algo } \\
\text { con las dos palmas de la mano; llevar un } \\
\text { objeto de las asas }\end{array}$ & & rojo \\
\hline -muku 'convergente' & $\begin{array}{l}\text { arrerar ganado; llevar recipiente plano; llevar } \\
\text { del brazo o con soga }\end{array}$ & comprar & \\
\hline -nuqa 'ubicativo' & empujar; llevar barro; llevar en el regazo & & \\
\hline -rpaya 'ubicativo' & $\begin{array}{l}\text { llevar un objeto tomado de las asas; } \\
\text { desplazamiento de agua y barro; llevar }\end{array}$ & & rojo \\
\hline -xata 'ubicativo' & $\begin{array}{l}\text { llevar un objeto tomado de las asas; correr, } \\
\text { volar; caminar como borracho }\end{array}$ & & \\
\hline
\end{tabular}


CAJAVILCA VERAMENDI \& CAJAS ASCANOA - REPENSANDO LOS...

Cuadro 2: Verbos y nombres que reciben la sufijación de los SD en aimara (Hardman 2001) ${ }^{10}$

\begin{tabular}{|c|c|c|c|}
\hline SD & Verbos de movimiento & Otros verbos & Nominales \\
\hline -xäsi 'estático' & $\begin{array}{l}\text { llevar; llevar un bulto en la espalda; } \\
\text { llevar niño en brazos }\end{array}$ & & \\
\hline -xaru 'preparativo' & llevar; ir, caminar & & \\
\hline -t’a 'momentáneo' & ir, caminar; llevar & hablar, preguntar & bebé \\
\hline$-n i$ 'proximador' & llevar & & \\
\hline -qa 'abajo' & $\begin{array}{l}\text { ir, caminar; llevar; arrastrar porción } \\
\text { de tierra; nadar }\end{array}$ & soplar, dormir, saber & \\
\hline -ranta & - & - & - \\
\hline -nta 'dentro' & llevar; arrear; nadar & soplar, hablar, llorar & calor \\
\hline -ta 'arriba' & $\begin{array}{l}\text { llevar; ir, caminar; llevar en la mano } \\
\text { objetos sólidos, pequeños y esféricos; } \\
\text { ir en tumulto; seguir; arrear }\end{array}$ & cavar, comprar & $\begin{array}{l}\text { bueno, negro, } \\
\text { poco, recto, } \\
\text { anciano }\end{array}$ \\
\hline -kata 'a través de' & llevar; ir en tumulto; arrear & $\begin{array}{l}\text { ver, contar, sentarse, vender, } \\
\text { informar, dar }\end{array}$ & calor \\
\hline -su 'afuera' & llevar; arrojar & $\begin{array}{l}\text { comprar, crecer, hacer pared, } \\
\text { ver, soplar, llorar, bailar }\end{array}$ & habla \\
\hline -kipa 'alrededor de' & llevar & ver, pesar, hablar & \\
\hline -naqa 'sin dirección' & ir, caminar; llevar & ver & \\
\hline -tata 'dispersador' & llevar; ir en tumulto & reventar & calor \\
\hline -waya 'distanciador' & ir, caminar & hablar & \\
\hline -thapi 'recolector' & $\begin{array}{l}\text { llevar; arrastrar porción de tierra; ir, } \\
\text { caminar }\end{array}$ & atar & casa \\
\hline -nuku 'lejos' & $\begin{array}{l}\text { llevar objeto en mantel; llevar; ir, } \\
\text { caminar }\end{array}$ & bailar & \\
\hline -nuqa 'situador' & llevar; arrojar & & casa \\
\hline -rpaya 'múltiple' & $\begin{array}{l}\text { hacinar horizontalmente paja u } \\
\text { objetos largos; correr; llevar; arrear }\end{array}$ & cortar, atar & \\
\hline -xata 'encima de' & $\begin{array}{l}\text { llevar; ir, caminar; arrear; correr; } \\
\text { cubrir con objeto pesado }\end{array}$ & & chacra \\
\hline
\end{tabular}

Una primera observación es que el aimara tiene verbos muy específicos de movimiento que señalan la «manera» del movimiento, indicando incluso la figura y la forma de transporte; por ejemplo, aya 'llevar palo u objeto alargado en la mano'. Al parecer, estos verbos específicos ocuparían un espacio innecesario en el lexicón de la lengua aimara, ya que es más económico componer infinidades de eventos de movimiento con un solo verbo de significado más general, tal como el verbo llevar del español. No obstante, téngase en cuenta que los verbos aimaras son raíces breves de dos sílabas y la afijación de los SD termina de completar la información de la trayectoria del movimiento. ¿Habría una relación causal entre la creación de los SD y la presencia de los verbos de manera del

${ }^{10} \mathrm{El}$ orden de esta lista de sufijos está basado en la lista del Cuadro 1. El sufijo -ranta no es reportado por Hardman (2001). 
movimiento? Pues todo indicaría que sí. Los SD emergieron vía gramaticalización para completar el sentido de la trayectoria en los múltiples verbos de manera que carecían inherentemente de este componente. No es un hecho aislado que el aimara tenga hasta 34 tipos de verbos-llevar (cf. Huayhua 2009). La cantidad de SD en aimara se ajusta a la cantidad de verbos de manera del movimiento, por lo tanto, podríamos conjeturar que una lengua con escasos verbos de manera no tendría un amplio inventario de SD o, en todo caso, tendría solo unos cuantos.

Por cierto, el aimara reporta verbos de trayectoria equivalentes a subir, bajar, salir, entrar; no obstante, la mayoría de ellos son derivaciones que involucra la agregación de SD. Los verbos de manera jala 'correr, volar' y sara 'caminar' son los más comunes en estas formaciones: jal+su 'subir'; jala+nta 'entrar'; jala+qa 'bajar'; sara+qa 'descender'; saratta 'subir' (cf. Huayhua 2009; Coler 2014). Los verbos makhata 'subir' y manta 'entrar' contienen los SD -kata 'ascendente' y -nta 'introductivo', respectivamente, y el verbo extinto ma- 'ir' reportado por Bertonio (1879). Por otro lado, el verbo mistu 'salir' no es segmentable sincrónicamente, aunque es probable que esté conformado con el antiguo sufijo -thusnu 'salirse del montón o de la manada' (Bertonio 1612: 112) y una raíz verbal desconocida *mi(s).

En suma, el aimara es una lengua que prioriza la manera del movimiento, siendo así una lengua que Slobin (2004: 250) denomina high-manner-salient language, ya que la información de manera se proporciona recurrentemente en los eventos de movimiento; en contraposición, hay lenguas que priorizan más bien la trayectoria, donde la información de manera se pasa por alto o apenas se indica mediante un adjunto. Una consecuencia tipológica de las lenguas de alta saliencia de manera es un rico y variado léxico de verbos o morfemas de manera (ibíd.: 251), tal como observamos en el aimara ${ }^{11}$ y su rico inventario de verbos-llevar. ${ }^{12}$

\subsection{Los SD en el jaqaru}

La lengua jaqaru, hablada en la provincia de Yauyos, sierra de Lima, es una variedad más conservativa, pues su asiento se considera una isla lingüística de lo que fue una vez un área extensa de lenguas o dialectos aimaras en la costa y sierra central del Perú. Estructuralmente, no se diferencia del aimara; las diferencias son más que todo de tipo lexical y fonológico (cf. Hardman 2000).

El jaqaru tiene el mismo sistema de SD que su lengua hermana, el aimara; es decir, los SD se organizan adyacentes a la raíz verbal compartiendo la posición morfémica con sufijos aspectuales. Según Hardman (2000: 79) existen alrededor de 30 sufijos; entre ellos podemos encontrar los horizontales, verticales, rotativos, divergentes, convergentes y ubicativos que reporta Huayhua (2001) para la lengua aimara. La diferencia con el aimara yace en su forma fonética y, en algunos casos, en su semántica, por ejemplo, los sufijos -ta 'incoativo' y -qa

${ }^{11}$ El mismo Bertonio (1879) se da cuenta de la riqueza de verbos-llevar y verbos de movimiento con distinciones muy específicas y no deja de mencionarlos en una sección aparte.

${ }^{12}$ La literatura reporta el VM neutral apa 'llevar' sin ninguna especificación adicional, sin embargo, este mismo verbo habría sido antiguamente un VM de manera. Obsérvese que, en el jaqaru, apa tiene una distinción más específica, denota 'cargar, cargar a cuestas' (cf. Belleza 1995). 


\section{CAJAVILCA VERAMENDI \& CAJAS ASCANOA - REPENSANDO LOS...}

'descendente lento' del aimara se reportan como -pta 'ascender' y $-k^{h} a$ 'precipitante' en jaqaru, respectivamente. Entre los VM que reporta Hardman (2000: 81-86) y que reciben la sufijación de SD, la gran mayoría son verbos de manera.

\section{Los SD en el quechua}

El quechua es otra lengua andina originaria del Perú y es una de las lenguas nativas con mayor número de hablantes en Sudamérica. Su origen, desarrollo y estructura lingüística se explica en parte por su estrecha relación histórica con el aimara, ya que sus lenguas ancestrales compartieron alguna vez el mismo territorio en el centro occidental del Perú. Existen pensar en un origen sorprendentes semejanzas léxicas y gramaticales entre ambas lenguas que invita a pensar en un origen común, sin embargo, no es una teoría rigurosamente aceptada. ${ }^{13}$ Así, parte de la estructura gramatical del quechua se debe a la copia de paradigmas completos desde el protoaimara; no obstante, el caso de los SD quechua se muestra, más bien, defectivo si comparamos con el numeroso paradigma de los SD del aimara.

Los SD del quechua pueden ser identificados a partir del análisis diacrónico de los dialectos quechuas. Se ha encontrado cinco SD típicos que se unen a los verbos en posición preflexiva: -rku 'arriba', -rpu 'abajo', -rqu 'afuera', -yku 'adentro' y el cislocativo -mu. Según Adelaar (2006: 130), ningún dialecto quechua conserva hoy los cinco sufijos en total con sus respectivos significados direccionales. Cada dialecto ha reanalizado los sufijos de diferentes formas. A principios del siglo XVII, González Holguín (1842 [1607]) reportó los sufijos $-y k u$ 'hacia dentro, hacia abajo', -rqu 'hacia afuera, hacia arriba, hacia adelante' y -mu 'hacia acá' en el quechua de la época, ${ }^{14}$ lo que nos da entender que los sufijos $-y k u$ y -rqu denotaban más de un significado direccional, y sin mencionar sus valores aspectuales. El quechua de Pacaraos $^{15}$ (cf. Adelaar 1987), que no se ha establecido su afinidad con el QI ni con el QII, tiene los sufijos -rku 'arriba', -rpu 'abajo', $-y k u$ 'adentro' y -mu, los cuales todavía mantienen su significado direccional, mientras que -rqu asoma como elemento fosilizado en el verbo yarqu 'salir.' ${ }^{16}$ Ciertamente, el quechua de Pacaraos es el dialecto

${ }^{13} \mathrm{Al}$ margen de las teorías de parentesco genético entre las dos lenguas, la evidencia demuestra que sí hubo ciertamente procesos de convergencia. Respaldamos la idea de los focos iniciales separados de los ancestros quechuas y aimaras de Cerrón-Palomino (2010) y la teoría de la dirección del calco desde el protoaimara hacia el protoquechua de Adelaar (2010, 2012). Por ejemplo, se evidencia el calco de paradigmas completos como aquel de los sufijos transicionales de sujeto-objeto o el sistema de nominalizadores que subordinan al verbo de las cláusulas completivas y relativas. Véase más al respecto en Cerrón-Palomino (2008) y acerca del léxico y fonología compartida en Emlen (2017).

${ }^{14}$ Podemos agregar a la lista los sufijos -rkacha y -rpaya 'enviar, distribuir' (cf. González Holguín 1842: 251), evidentemente cognados con los sufijos aimaras -wacha -waya 'divergente indeterminado' y rpaya 'ubicativo sin prevención'.

${ }^{15}$ Pacaraos es un distrito de la provincia de Huaral, en la sierra norte del departamento de Lima.

${ }^{16} \mathrm{El}$ quechua del Huallaga tiene los verbos de trayectoria inherente yarku 'subir', yarpu 'bajar', yarqu 'salir' y yayku 'entrar' que, a excepción de yayku, no son muy usados por los informantes de Weber (1996). En ellos se puede observar los SD fosilizados a una antigua raíz *ya de significado oscuro. De la misma forma, encontramos los verbos lexicalizados qarku 'amontonar', qarpu 'tirar abajo', qarqu 'sacar a la fuerza', qayku 'meter al corral' formados históricamente con SD y una desconocida raíz * qa (ibíd.). González Holguín (1608) reporta los verbos <yaccani> yaqa- 'seguir (a alguien)' y <ccatini> qati- 'seguir el rastro', 'llevar ganado' que parecen estar relacionados con las formas anteriores. En todo caso, es más probable que las formas *ya y * qa habrían sido verbos de manera. 
que más SD ha conservado (cuatro en total), una situación que difícilmente se ve en otros dialectos quechuas. Veamos algunos cambios semánticos que han sufrido los sufijos en el quechua del Huallaga y en el quechua del Cuzco.

En el quechua del Huallaga, rama QI, Weber (1996: 179) denomina «sufijos direccionales» a cuatro sufijos verbales: -rku 'arriba', -rpu 'abajo', -rqu 'afuera' y $-y k u$ 'adentro'. De estos, los dos últimos, -rqu y $-y k u$ prácticamente ya han perdido su significado direccional y actualmente se los emplea como sufijos de aspecto o modo para denotar rapidez, sorpresa, éxito, impacto o cortesía en la acción verbal. Las etiquetas 'afuera' y 'adentro' se emplean según un criterio diacrónico, aunque no evoquen precisamente aquellos significados. Morfológicamente, el autor los agrupa junto con los sufijos pretransicionales porque se posicionan antes de los sufijos flexivos o sufijos transicionales del verbo. A este grupo, podemos añadir el sufijo pretransicional - $m u$ 'lejos' (ibíd.: 197), el cual, cuando se une a VM, confiere un sentido cislocativo a la dirección del movimiento; por ejemplo, los verbos llalli 'correr' y qati 'arrear (hacia allá)' con el sufijo -mu resultan llallimu 'correr (viniendo)' y qatimu 'arrear (hacia acá)', respectivamente.

En el quechua del Cuzco, rama QII, Itier (1997) reporta los sufijos antes mencionados: $y k u,-r q u,-k u,-m u$ у $-p u$. Con respecto al sufijo $-y k u$, aparte de los sentidos aspectuales o modales, cuando se une a VM denota 'hacia dentro' o 'hacia la parte inferior'. El sufijo $-r q u$, en cambio, ya no denota dirección 'hacia el exterior', sino solo conserva un valor aspectual, indica que la acción del verbo se realiza de forma repentina o inesperada. El sufijo - $k u$ indica que la acción se orienta hacia el sujeto, para su beneficio, para su lado, sin los otros. A diferencia de $-k u,-m u$ y - $p u$ todavía conservan un significado direccional. Con verbos de movimiento, $-m u$ у - $p u$ indican que la acción se orienta hacia un punto dentro del campo de visión y hacia un punto fuera de él, respectivamente. Similar a los sufijos II del aimara, - $-т и$ у - $-р u$ van a afectar la interacción de los complementos del verbo, sobre todo cuando se unen a verbos de no movimiento: ${ }^{17}$

$-m u \rightarrow$ dentro del campo de visión / acción orientada hacia un segundo actante

$-p u \rightarrow$ fuera del campo de visión / acción orientada hacia un tercer actante

Agregamos a la lista de los SD el sufijo -ykacha 'dispersativo', que unido a VM indica que la acción se realiza en múltiples direcciones (cf. Itier 1997: 94); es similar al sufijo aimara -wacha 'divergente indeterminado'.

En síntesis, los SD del quechua no son tan ricos y variados como los del aimara. El desuso y la lexicalización del par raíz+SD ha sido permanente en el quechua, mientras que en el aimara se conserva hasta ahora la mayoría de los SD con sus significados direccionales.

${ }^{17}$ Por ejemplo, en la oración tayta-n-man willa-rqa-ka-mu-n 'rápidamente fue a decirle a su padre', el sufijo - $m u$ indica que el verbo willa 'decir' se orienta hacia tayta- $n$ 'su padre' que es un actante dentro del campo de visión. 


\section{CAJAVILCA VERAMENDI \& CAJAS ASCANOA - REPENSANDO LOS...}

\section{Los SD en otras lenguas nativas sudamericanas}

En esta sección, indagaremos la presencia de los SD en otras lenguas nativas de Sudamérica, para lo cual hemos elegido preferentemente lenguas del extremo occidental de la Amazonía, tomando al Perú como eje central (véase Mapa 1). Las lenguas se ubican entre los paralelos $3^{\circ} \mathrm{N}$ y $23^{\circ} \mathrm{S}$, abarcando los siguientes países: Perú, Brasil, Bolivia y Argentina. En el Cuadro 3 mostramos las familias lingüísticas de cada una de las lenguas examinadas; entre estas tenemos lenguas de la familia pano, tacana, tucano, arawá, uruchipaya, arawak, bora-witoto, katukina, tupí-guaraní, chapacura y una lengua aislada. A continuación, mostramos el estudio de cuatro lenguas (ashéninka, matsés, kashibokakataibo y jarawara) con respecto al empleo de los SD en los verbos de movimiento, mientras que, para el resto de lenguas, sus resultados serán indicados directamente en el Cuadro 3.

\subsection{Ashéninka (arawak)}

El ashéninka ${ }^{18}$ tiene propiamente tres sufijos direccionales con valor deíctico: $-a p$ 'meta', -an 'origen' y - av 'O-meta orientada' (cf. Mihas 2010). Estos SD se sufijan tanto a verbos de manera como a verbos de trayectoria. En (16) vemos que la derivación del sufijo - an al verbo de manera $k i$ - 'cargar algo en la espalda' indica movimiento lejos del centro deíctico, a diferencia del ejemplo (15), que solo informa la manera de llevar algo sin especificar la trayectoria:

(15) Ashéninka (Mihas 2010: 57)

$\mathrm{i}=\mathrm{ki}-\mathrm{i}=\mathrm{ri}$

$3 \mathrm{~m} . \mathrm{A}=1$ levar-REAL $=3 \mathrm{~m} . \mathrm{O}$

'Él lo llevaba en su espalda'

(16) Ashéninka (Mihas 2010: 57)

$\mathrm{i}=\mathrm{ki}-\mathbf{a n}-\mathrm{ak}-\mathrm{i}=\mathrm{na}$

$3 \mathrm{~m} . \mathrm{A}=$ llevar-DIR-PRF-REAL $=1$ SG.O

'Él me llevó en su espalda (alejándose)'

Por otro lado, en los ejemplos (17) y (18), -ap 'meta' indica movimiento hacia el centro deíctico:

(17) Ashéninka (Mihas 2010: 274)

$\mathrm{o}=$ shiy-ashi-t-ap-ak-a $=$ na

$3 \mathrm{~nm} . \mathrm{A}=$ correr-APL.INT-EP-DIR-PRF-REAL $=1$ SG.O

'ella corrió [donde estaba el bebé] con la intención de ayudarme'

${ }^{18}$ La lengua ashéninka descrita por Mihas (2010) es una lengua arawak del subgrupo campa, hablada en el curso superior del río Perené, provincia de Chanchamayo, Junín. Esta zona es conocida como la selva central del Perú, al este de las estribaciones andinas. 
(18) Ashéninka (Mihas 2010: 250)

antaro-ite manitzi $\mathrm{i}=$ ken-ap-ak-i $\quad \mathrm{o}=$ nary-ak-a=ra

gran-AUM tigre $3 \mathrm{~m} . \mathrm{S}=$ caminar-DIR-PRF-REAL $3 \mathrm{~nm} . \mathrm{S}=$ yacer-PRF-REAL $=\mathrm{ADV}$

'Un enorme tigre se dirigió donde las mujeres yacían [dormidas]'

No obstante, la lengua emplea otros elementos para indicar la trayectoria como, por ejemplo, el adverbio intakiro 'afuera':

(19) Ashéninka (Mihas 2010: 159)

kapicheeni ironyaka $=$ ha kamatsa-vai-t-ah-i=na iNtakiro

poco ahora $=$ ENF arrastrarse-DUR-EP-REG-REAL $=1$ SG.o afuera

'Poco a poco comencé a arrastrarme hacia el exterior'

Otros verbos, como atai- 'ir hacia arriba', shitov- 'salir, escapar', especifican inherentemente la trayectoria, sin la manera del movimiento. Sin embargo, el verbo shitoves capaz de recibir la flexión del SD -an 'origen' aunque parezca redundante:

(20) Ashéninka (Mihas 2010: 188)

$\mathrm{o}=$ shitov-an-ak-i osheki $\mathrm{n}=$ ira-ni tsikiri tsikiri

$3 \mathrm{~nm} . \mathrm{s}=$ escapar-DIR-PRF-REAL mucho 1sG.POS=sangre-POS IDEO IDEO

'Mi sangre brotó como arroyo'

De hecho, el ashéninka tiene verbos de manera de alta especificidad parecidos a los del aimara. Véase los siguientes verbos de manera extraídos del diccionario de Payne (1980): $q y$ - 'cargar algo en la espalda con huato', katha- 'cargar en brazos, llevar a alguien de la mano', thoma- 'cargar bebé, llevar en brazos', ana- 'cargar sobre el hombro', amatsinka'andar muy despacio', shire- 'andar por la orilla del río', anashi- 'andar por', anii- 'andar por', $k i$ - 'sacar líquido con vaso', kamaa- 'sumergirse para sacar algo de un hueco', entre otros. La mayoría de estos verbos de movimiento son transitivos como ocurre así con anashi- 'andar por' y anii- 'andar por'. Este último verbo tendría la particularidad de expresar tanto manera como trayectoria ('hacia abajo') según Mihas (2010), quien reporta los dos casos: en (21), observamos que anii- expresa manera, mientras que en (22), aniiexpresa trayectoria:

(21) Ashéninka (Mihas 2010: 231)

no=tsarov-a-niNt-atz-i $\quad \mathrm{n}=$ anii-t-e tsiteni

1SG.S=temer-EP-DIM-PRO-REAL 1SG.S=caminar-EP-IRR de.noche

'Tengo un poco de miedo de caminar en la oscuridad'

(22) Ashéninka (Mihas 2010: 103)

$\mathrm{i}=\mathrm{v}-$-anii-t-ap-ak-i $=$ na

$3 \mathrm{~m} . \mathrm{A}=\mathrm{CAU}-$ descender-EP-DIR-PRF-REAL $=1$ SG.O

'Él me bajó [cuando estaba inconsciente]' 
Todavía queda cierta duda si anii- realmente expresa dirección hacia abajo o es el SD $a p$ el que atribuye el sentido direccional en (22). Lo cierto es que Mihas (2010: 296) reporta hasta tres verbos-caminar: kin-, anii-, avis-, los cuales no parecen confundirse con el verbo ha- 'ir'. Ciertamente cada uno de estos tres verbos-caminar deben distinguirse semánticamente, aunque Mihas los presenta como si fueran sinónimos. En la variedad asháninka, ${ }^{19}$ es notorio cómo el SD -an le otorga el sentido direccional al verbo de manera 'nadar', mucho más específico que solo el sentido de 'alejarse':

(23) Asháninka (Kindberg 1980: 70)

n-ama-t-an-ak-e eni

1SG.S-nadar-EP-DIR-PRF-REAL río

'Yo nado al otro lado del río'

\subsection{Matsés (pano)}

El matsés ${ }^{20}$ (cf. Fleck 2003) emplea SD que se adjuntan próximos al verbo; aunque solo se puede usar un sufijo direccional por verbo. Ellos indican la dirección del desplazamiento del sujeto mientras se realiza la acción verbal. Con excepción de -bud 'hacia abajo', -do 'hacia arriba' y -tuid 'parar y hacer/hacer al llegar', los SD -tan, -uan y sus variantes (-cuidan, -bidan, -cuëtsen, -bëtsen...) tienen al acto de habla como su centro deíctico. Ciertamente, estos sufijos tienen una función deíctica espacial, parecidos a los SD del ashéninka.

Con los sufijos -tan 'ir' y -uan 'venir':

(24) Matsés (Fleck 2003: 816)

bëdi-dapa- $\varnothing$ pudun-tan pudun-tan-quid matses- $\varnothing$ pe-nuec

jaguar-grande-ABS (RDP=DIS) saltar-ir-HAB matsés-ABS comer-PROP:S/A>S

'El jaguar salta hacia él para comer al matsés'

(25) Matsés (Fleck 2003: 1081)

beduan bed-uan-tsëcquio-en tëshuan tësh-uan-quin

$(\mathrm{RDP}=\mathrm{DIS})$ agarrar-venir-ADJZR:DERO-ADVZR:TR $(\mathrm{RDP}=\mathrm{DIS})$ jalar-venir-mientras:S/A>A

'Mientras que continuamente [los murciélagos] vienen para agarrar y arrancar pedazos'

Estos sufijos son productivos con cualquier tipo de verbo, sean o no de movimiento, por el mismo sentido que implica; es decir, los sufijos solo sitúan la acción del sujeto con respecto al centro deíctico. Es, en un aspecto, parecido a la productiva perífrasis verbal del español ir a VERBO o venir para VERBO:

${ }^{19}$ La lengua arawak asháninka es una variedad reportada por Kindberg (1980), hablada entre los ríos Tambo y Ene (siendo el río Tambo la continuación del Perené) en la provincia de Satipo, Junín. El asháninka está estrechamente emparentado con el ashéninka.

${ }^{20}$ El matsés es una lengua amazónica de la familia pano hablada en el límite entre Perú y Brasil, a $5^{\circ} 17^{\text {, }}$ de latitud sur y $73^{\circ} 9^{\prime}$ de longitud oeste aproximadamente (Fleck 2003). 
(26) Matsés (Fleck 2003: 456)

posh poshca-tan-o-sh

$(\mathrm{RDP}=\mathrm{DIS})$ hacer.agujero-ir-PAS-3

'Fue a abrir muchos hoyos'

Una variante del andativo -tan es el sufijo -cuidan en verbos transitivos, y -bidan en cualquier verbo. Estos sufijos son semánticamente parecidos a -tan 'ir', excepto que el sujeto continúa alejándose del centro deíctico después de realizar la acción verbal. De la misma manera, los sufijos -cuëtsen y -bëtsen son los contrarios a -cuidan y -bidan y, por lo tanto, son equivalentes a-uan 'venir':

(27) Matsés (Fleck 2003: 370)

isun-cuidan-o-sh

orinar-ir.hacer.ir-PAS-3

'se detuvo a orinar mientras iba'

(28) Matsés (Fleck 2003: 370)

chimu-cuëtsen-o-sh

defecar-venir.hacer.venir-PAS-3

'se detuvo a defecar de camino aquí'

Los sufijos anteriores dan cuenta de una sola detención en la marcha, otros sufijos refieren a una acción que se realiza sin parar o que para varias veces para realizar la acción. Estos sufijos son -ban, -bë y -ben, para verbos transitivos, y -nid, -cho y -cuen, para verbos intransitivos.

(29) Matsés (Fleck 2003: 371)

is-ben-o-mbi

mirar-mientras.pasar:TR-PAS-1A

'yo miré mientras pasaba'

(30) Matsés (Fleck 2003: 371)

mamën-cho-o-bi

reír-mientras.venir:INT-PAS-1s

'vine riéndome'

(31) Matsés (Fleck 2003: 371)

onque-cho-o-sh

hablar-mientras.venir:INT-PAS-3

'él habló todo el camino hasta aquí'

Como dijimos anteriormente, los sufijos -tuid 'parar y hacer/hacer al llegar', -bud 'hacia abajo' y -do 'hacia arriba' no especifican la dirección con respecto a un centro deíctico. Por lo tanto, la información de la trayectoria tiene un sentido más general, tal 
como los SD del aimara. ${ }^{21}$ El significado que confiere al verbo a menudo es especial y no tan predecible.

(32) Matsés (Fleck 2003: 372)

aton shëcuë ënëd-ac-no nid-quid tsad-tuid-ec

3GEN hoyo fin-ACT.NML-LOC ir-HAB sentar-hacer.al.Ilegar-PROP:S/A>A

'[el armadillo] va hasta donde termina su agujero para sentarse allí'

(33) Matsés (Fleck 2003: 374)

titado tësh-bud tësh-bud-quid quëuëte-ua-shun

p.de.durazno ( $\mathrm{RDP}=\mathrm{DIS})$ quitar-hacia.abajo-HAB anzuelo-VBL:hacer-después:s/A>A 'Después de hacer un gancho, bajan muchos frutos de la palma de durazno'

(34) Matsés (Fleck 2003: 374)

pudun-do

saltar-hacia.arriba

'subir'

(35) Matsés (Fleck 2003: 374)

cuibi-do-quin

desde.borde-hacia.arriba-mientras: $\mathrm{S} / \mathrm{A}>\mathrm{A}$

tabado-quid

'comienzan a construir los lados [de la jarra]'

empezar-HAB

Los sufijos -bud y -do no ocurren en todos los verbos, por lo tanto, no son tan productivos como los sufijos anteriores. No obstante, -bud y -do serían muy antiguos ya que aparecen fosilizados en ciertas raíces verbales. Por otro lado, los sufijos -ben $\sim$ cuen, -ban, -bud y -do ocurren también como sufijos de aspecto verbal.

\subsection{Kashibo-kakataibo (pano)}

Zariquiey (2011: 395) clasifica los SD del kashibo-kakataibo ${ }^{22}$ en tres clases: direccionales aspectuales, direccionales de trayectoria y direccionales ir/venir. Los primeros indican que la acción verbal se realiza mientras el sujeto se está desplazando, por lo tanto, son más comunes en verbos de no movimiento; en consecuencia, no son propiamente SD. Los de trayectoria son -ru 'hacia arriba', but, pat, -pakët 'hacia abajo' y -at -(a) rat y -akët $\sim$-(a)rakët 'trayectoria curva'. Los direccionales ir/venir son -kian, -bian 'ir', -kwatsin, -bëtsin 'venir' y -kwain, -buin 'pasando por', los cuales se distinguen según la sufijación en verbos intransitivos o transitivos. Como dato interesante, Zariquiey (2011: 426) deja entrever la existencia de dos SD extintos con el sentido de 'afuera': *-chi y *-kut. Estos sufijos serían formas fosilizadas en palabras como ëchi 'quitar', bëchi

${ }^{21}$ Excepto el sufijo aimara - $n i$ 'cislocativo'.

${ }^{22}$ El kashibo-kakataibo es otra lengua pano del Perú, siendo la lengua pano más occidental. La variedad reportada por Zariquiey (2011) es hablada en la provincia de Padre Abad, departamento de Ucayali. 
'arrancar', puchi 'quitarle los intestinos a un animal', pikut 'salir', chikut 'aparecer', mapikut'sacarle la cabeza'.

\subsection{Jarawara (arawá)}

La lengua jarawara, ${ }^{23}$ al igual que el aimara, utiliza SD de amplios sentidos que se unen a verbos flexivos o a auxiliares de verbos no flexivos. Dixon (2004) los separa en dos grupos: sufijos de localización y dirección y sufijos de movimiento y dirección.

Los sufijos de localización y dirección: entre estos tenemos el sufijo -misa 'arriba' que puede referir a movimientos ascendentes, golpes hacia arriba, acción de sostener, jalar, ascender, saltar, llevar algo en la espalda, entre otros.

(36) (Dixon 2004: 141)

boroko mee horo na-misa-makiha

cerdo(m) 3NSG.A tirar AUX-arriba-seguir

'ellos siguen tirando del cerdo hacia arriba (hacia la canoa)'

(37) (Dixon 2004: 141)

faha tasi na-misa-ke

agua(f) pasar.por.agujero AUX-arriba-DEC

'el agua entra por un agujero [en la canoa]'

Para indicar movimiento hacia abajo se utiliza el sufijo -risa 'abajo', el cual junto al auxiliar -na- resulta -nisa:

(38) (Dixon 2004: 142)

jama mati ho.horo nisa-ne

$\operatorname{cosa}(\mathrm{f})$ cuerda $+\mathrm{f}$ RDP.tirar aux + abajo-MSP

'tiró de la cuerda un poco hacia abajo'

El sufijo -riwaha 'a través' se une con el verbo flexivo - $k a$ - 'estar en movimiento':

(39) (Dixon 2004: 142)

faja otaa ka-ka-riwaha-ma otaa-ke fahi

entonces 1EXC.S APL-en.movimiento-a.través-retorno 1EXC-DEC allíno.visible 'entonces nosotros cruzamos de nuevo por el río allí'

Otros sufijos de localización y dirección son -tima 'corriente arriba', -basa 'hacia/ por el borde', -joma 'pasar a través de una abertura', -kosa 'entre dos extremos' (cf. Dixon 2004: 141-144).

${ }^{23}$ El jarawara es una lengua amazónica de la familia arawá hablada al oeste de la ciudad de Lábrea, en el estado brasileño de Amazonas. Sus coordenadas aproximadas son $7^{\circ} 24^{\prime}$ de latitud sur y $65^{\circ} 0^{\prime}$ de longitud oeste (Dixon 2004). 
Los sufijos de movimiento y dirección: por ejemplo, el sufijo $-k I$ 'venir' refiere movimiento hacia el lugar donde se encuentra el hablante. Cuando funciona con verbos no flexivos de movimiento, este se une al auxiliar -na-:

(40) (Dixon 2004: 471)

horo o-ka-na-ke-hina-ha

tirar 1SG.A-APL-AUX-venir-IRR-DEP

'casi yo lo empujo [al agua]'

Con verbos no flexivos que no son de movimiento refiere a una acción que sucede mientras el sujeto está llegando:

(41) (Dixon 2004: 148)

mee ati koro na-ke-hara-ke

3NSG habla ser.audible AUX-venir-IPAS.EVI-DEC

'el sonido de su conversación se oía mientras ellos se acercaban'

Cuando $-k I$ 'venir' se une a verbos flexivos de movimiento, no requiere auxiliar y, aunque la expresión resultante es en parte redundante, su sufijación implica información de la meta:

(42) (Dixon 2004: 477)

sorowaha mee ka-kisa-ke-hani mee

sorowahá 3NSG.S APL-ir.río.abajo-venir-IPAS.EVI 3NSG.DEP

'los sorowahá se movían río abajo'

El sufijo -witI 'desde un lugar, hacia afuera desde un centro' se une a verbos flexivos como - $k a$ - 'estar en movimiento'; no obstante, cuando se une a verbos no flexivos, el auxiliar -na- es omitido, véase los ejemplos a continuación:

(43) (Dixon 2004: 151)

jama foo o-witi-ne o-ke

cosa(f) soplar 1SG.A-desde.lugar-CON 1SG-DEC

'estoy soplando migajas [fuera de la mesa]'

(44) (Dixon 2004: 151)

jowi jora to-witi-ka

mono(m) saltar fuera-desde.lugar-DEC

'el mono está saltando [entre los árboles]'

Otros sufijos de movimiento y dirección son -ma 'atrás', 'regresar' y -makI 'seguir' (cf. Dixon 2004: 149-151).

En suma, siguiendo el mismo análisis para las otras lenguas nativas, elaboramos el Cuadro 3, tomando en cuenta las consideraciones de la sección 3, y el Mapa 1. No obstante, aunque hemos considerado los sufijos cislocativos y translocativos como SD, 
los distinguimos de los efectivos SD. Así, las lenguas con SD productivos están marcadas con símbolo de verificación $(\checkmark)$ y las lenguas con SD no tan productivos están marcadas con la descripción «limitado». Un tercer grupo consta de las lenguas que no tienen SD y están marcadas con guion (一).

Cuadro 3: Resumen de la ocurrencia de SD en 26 lenguas nativas de Sudamérica

\begin{tabular}{|c|c|c|c|c|}
\hline & Familia & Lengua & SD & Detalles \\
\hline 1 & aimaraica & $\begin{array}{l}\text { aimara (Huayhua 2001; } \\
\text { Hardman 2001) }\end{array}$ & $\checkmark$ & Ver $\S 4$. \\
\hline 2 & aimaraica & jaqaru (Hardman 2000) & $\checkmark$ & Ver $\S 4$. \\
\hline 3 & quechua & Pacaraos (Adelaar 1987) & $\checkmark$ & Ver $\S 5$. \\
\hline 4 & pano & matsés (Fleck 2003) & $\checkmark$ & Ver $\S 6$. \\
\hline 5 & pano & shipibo (Loriot et al. 1993) & $\checkmark$ & $\begin{array}{l}\text { Tiene los SD -tan 'ir y volver', -kain -bain } \\
\text { 'yéndose', -kiran -beiran 'viniendo', -pake } \\
\text { 'bajando', -ina 'yendo arriba', los cuales se } \\
\text { ubican cerca de la raíz, en las casillas de los } \\
\text { sufijos mediales del verbo. }\end{array}$ \\
\hline 6 & pano & $\begin{array}{l}\text { yaminahua (Eakin 1991; } \\
\text { Faust y Loos 2002) }\end{array}$ & $\checkmark$ & $\begin{array}{l}\text { Tiene los sufijos direccionales: translocativos } \\
\text {-kaĩl-faĩ 'ir', cislocativos -kerã/-ferã } \\
\text { 'venir', -pake/-pa 'abajo', -ini 'arriba'. Se } \\
\text { sitúan después de los sufijos derivativos y } \\
\text { modales. }\end{array}$ \\
\hline 7 & pano & $\begin{array}{l}\text { k a s h ibo-k a k a t a i bo } \\
\text { (Zariquiey 2011) }\end{array}$ & $\checkmark$ & Ver $\S 6$. \\
\hline 8 & pano & iskonawa (Zariquiey 2015) & $\checkmark$ & $\begin{array}{l}\text { Tiene los SD -beran, -keran 'venitivo', } \\
\text {-bain, -kain 'andativo', -bokon, -ake 'dando } \\
\text { la vuelta', -kawan 'pasando, cruzando', } \\
\text {-pake 'bajando', -ina 'subiendo'. }\end{array}$ \\
\hline 9 & tacana & cavineña (Guillaume 2008) & $\checkmark$ & $\begin{array}{l}\text { Tiene los SD -tsura 'subir', -bute/butya } \\
\text { 'bajar' y -sikwa 'ir lejos' que se ubican } \\
\text { adyacentes a la raíz verbal, antes de los } \\
\text { sufijos de cambio de valencia. }\end{array}$ \\
\hline 10 & tucano & wanano (Stenzel 2004) & $\checkmark$ & $\begin{array}{l}\text { Los SD son verbos que se comportan como } \\
\text { sufijos y que, al igual que el aimara, se } \\
\text { ubican adyacentes a la raíz verbal y otros } \\
\text { sufijos aspectuales. Stenzel los identifica } \\
\text { como verbos dependientes. Entre estos están } \\
\text {-wa'a 'ir', -ta 'venir', -buria 'ir río abajo', } \\
\text {-yoha 'ir río arriba'. }\end{array}$ \\
\hline 11 & arawá & jarawara (Dixon 2004) & $\checkmark$ & Ver $\S 6$. \\
\hline 12 & quechua & Huallaga (Weber 1996) & Limitado & Ver $\S 5$. \\
\hline 13 & quechua & Cuzco (Itier 1997) & Limitado & Ver $\S 5$. \\
\hline
\end{tabular}


CAJAVILCA VERAMENDI \& CAJAS ASCANOA - REPENSANDO LOS...

\begin{tabular}{|c|c|c|c|c|}
\hline 14 & uru-chipaya & $\begin{array}{l}\text { chipaya (Cerrón-Palomino } \\
\text { 2006) }\end{array}$ & Limitado & $\begin{array}{l}\text { SD prestados del aimara. La mayoría de ellos } \\
\text { van camino a la fosilización; solo un sufijo es } \\
\text { regularmente productivo, el cis-translocativo } \\
\text {-zhki. }\end{array}$ \\
\hline 15 & arawak & ashéninka (Mihas 2010) & Limitado & $\begin{array}{l}\text { Solo SD deícticos: - } a p \text { 'meta', -an 'origen' y } \\
a v \text { 'O-meta orientada'. }\end{array}$ \\
\hline 16 & arawak & matsiguenka (Snell 2011) & Limitado & $\begin{array}{l}\text { Solo SD deícticos: -apa 'adlativo', -an } \\
\text { 'ablativo' y -av 'dirección contraria'. Se } \\
\text { ubican más alejados de la raíz, después de los } \\
\text { sufijos de cambio de valencia y otros sufijos } \\
\text { modales y temporales. }\end{array}$ \\
\hline 17 & arawak & yanesha (Duff-Tripp 1997) & Limitado & Solo SD deícticos: $-o s,-o m,-a^{\prime} n,-a p$. \\
\hline 18 & pano & yora (Lord 2016) & Limitado & $\begin{array}{l}\text { Se reportan dos grupos de sufijos } \\
\text { direccionales: los translocativos -kaĩ/-faĩ } \\
\text { 'ir' y los cislocativos -kerã/-ferã 'venir'. Se } \\
\text { sitúan cerca de la raíz verbal, similar a los } \\
\text { sufijos mediales del shipibo. }\end{array}$ \\
\hline 19 & bora-witoto & $\begin{array}{l}\text { bora (Thiesen 1996; } \\
\text { Thiesen y Weber 2012) }\end{array}$ & Limitado & $\begin{array}{l}\text { Tiene cuatro sufijos verbales (ocurren } \\
\text { también como verbos lexicales) que indican } \\
\text { dirección: -té 'ir a', -je 'regresar de', -va } \\
\text { 'venir', -iñu 'dejar'. No necesariamente } \\
\text { ocupan una posición contigua a la raíz. }\end{array}$ \\
\hline 20 & katukina & $\begin{array}{l}\text { katukina-kanamari } \quad \text { (Dos } \\
\text { Anjos 2011) }\end{array}$ & Limitado & $\begin{array}{l}\text { Tiene los SD deícticos -na 'centrífugo' y -dik } \\
\text { 'centrípeto'. De manera inusual, estos SD } \\
\text { tienen libertad para ligarse a verbos, nombres } \\
\text { y posposiciones. }\end{array}$ \\
\hline 21 & pano & shanenawa (Cândido 2004) & - & No se reportan SD. \\
\hline 22 & pano & hãtxa kuĩ (Kaxinawá 2014) & - & $\begin{array}{l}\text { Solo se reporta tres verbos que pueden } \\
\text { funcionar como partículas direccionales: } \\
\text { el translocativo } k a \text { 'ir' y los cislocativos } h u \\
\text { 'venir.sg', } b \dot{t} \text { 'venir.pl'. }\end{array}$ \\
\hline 23 & tupí-guaraní & tapiete (González 2005) & - & $\begin{array}{l}\text { La lengua emplea composición verbal para } \\
\text { indicar trayectoria. Contiene numerosos } \\
\text { verbos que expresan trayectoria inherente. }\end{array}$ \\
\hline 24 & tupí-guaraní & kamaiurá (Seki 2000) & - & $\begin{array}{l}\text { La lengua emplea verbos auxiliares (ho } \\
\text { 'ir', 'ut 'venir'), que al lado de verbos de } \\
\text { movimiento van a indicar la trayectoria. }\end{array}$ \\
\hline 25 & aislada & urarina (Olawsky 2006) & - & No se reportan SD. \\
\hline 26 & chapacura & oro waram (Apontes 2015) & - & $\begin{array}{l}\text { Algunos verbos pueden funcionar como } \\
\text { partículas direccionales (p. ej., tikin } \\
\text { 'ir directo', ki? 'descender', mama 'ir. } \\
\text { PL'), formando una serie verbal o verbos } \\
\text { compuestos. }\end{array}$ \\
\hline
\end{tabular}




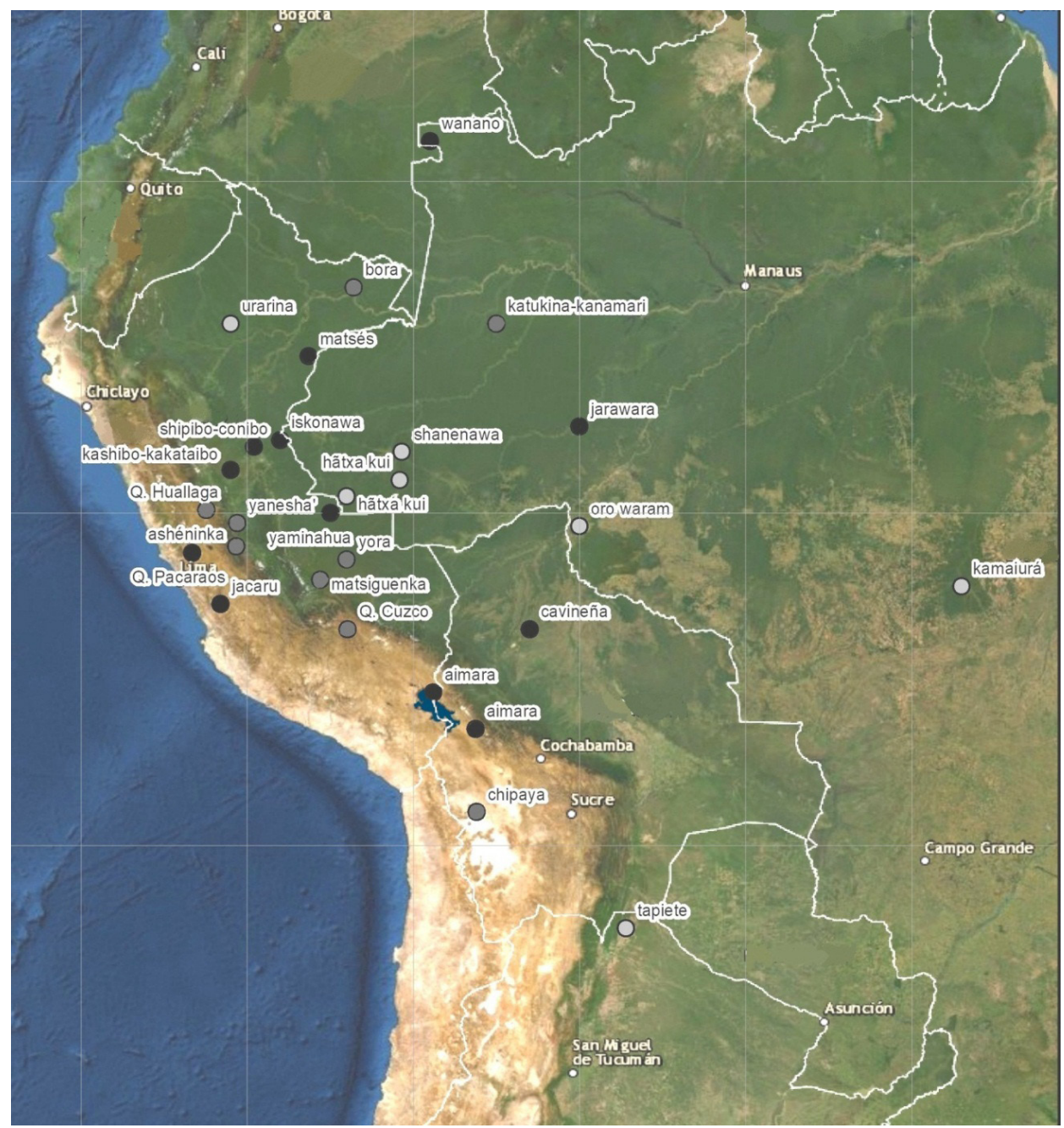

Mapa 1: Ubicación geográfica de las veintiséis lenguas sudamericanas examinadas. En gris oscuro, las lenguas que emplean SD; en gris medio, las lenguas que emplean SD limitado o solo deícticos; en gris claro, las lenguas que no emplean SD. Mapa de fondo proporcionado por Google Earth Pro [C 2020 Google LLC].

\section{Conclusiones}

Sintetizamos las conclusiones según dos criterios estructurales: uno intralingüístico, tomando las lenguas 1-20, y otro interlingüístico, tomando las 26 lenguas del Cuadro 3. Ilustramos a continuación.

En primer lugar, el Cuadro 3 no debe entenderse en términos de la presencia y carencia de la expresión de la trayectoria en los eventos de movimiento, pues la trayectoria es un componente obligatorio de estos eventos. Que una lengua no tenga SD no significa 
que carezca de los medios para expresar la trayectoria. Aquí nos hemos centrado en los SD como un sistema de morfemas verbales (satélites) que codifican la trayectoria del movimiento, así las lenguas del 1-11 presentan un inventario más o menos amplio de SD; las lenguas 12-20 tienen un inventario reducido de SD; mientras que las lenguas 21-26 no presentan SD y tienden, más bien, a codificar la trayectoria inherentemente en el verbo. No ha sido nuestro objetivo agotar todas las formas de codificar la trayectoria, que de hecho debe haber otras más, en estas 26 lenguas.

Acerca de la organización de los SD en la estructura verbal (criterio intralingüístico), en casi todas las lenguas que emplean SD, podemos distinguir un patrón que se repite con respecto a la incidencia de los SD en la estructura morfológica: la coincidencia en su posición preflexiva de los sufijos verbales y en el hecho de compartir la casilla morfémica con los sufijos aspectuales. Ciertamente, esto ha motivado que los SD sean considerados morfemas derivativos. Ahora bien, el hecho de que los SD se posicionan linealmente cerca de los sufijos aspectuales y tienden a ramificarse en conceptos más abstractos involucrados en el aspecto o modo gramatical, sugiere tentativamente que los sufijos aspectuales habrían sido en el pasado SD. Las lenguas que en la actualidad presentan escasos SD habrían tenido un inventario más amplio de SD en el pasado; por ejemplo, es un hecho que varios SD del aimara y del quechua se han regramaticalizado como sufijos aspectuales, y habría sucedido así también con el cavineña (cf. Guillaume 2008), el cual presenta un rico y variado inventario de sufijos aspectuales frente a solo tres SD.

El examen del Cuadro 3 desde la parte inferior hasta la parte superior (criterio interlingüístico) nos proporciona alguna luz acerca del camino evolutivo que siguieron los $\mathrm{SD}$ en la estructura de las lenguas. Los SD habrían empezado como verbos de trayectoria inherente, como aquellos que emplea el oro waram (ítem 26 del cuadro) y otras lenguas del tercer grupo; véase que dichos verbos se usan al lado de verbos de movimiento formando una serie verbal. Precisamente, las lenguas 21-26 suelen afijar pocos morfemas a la raíz, algo que ya había notado Payne (1997: 307) con respecto a la alta productividad de verbos seriales en lenguas con escasa morfología verbal. Téngase en cuenta que estos verbos pueden llegar a atribuirse la flexión verbal, es decir, se convierten en verbos auxiliares, tal como sucede en kamaiurá (ítem 24 del cuadro). No obstante, la cercanía entre los dos elementos, como rastro de la primigenia composición verbal $\mathrm{V}+\mathrm{V}$, tiene consecuencias en la estructura morfológica en su camino a la gramaticalización — sugerentemente los SD reportados se ubican casi siempre cerca a la raíz verbal- Posteriormente van perdiendo autonomía y se dan casos como el wanano (ítem 10), en donde verbos léxicos se comportan como sufijos. Finalmente, gramaticalizan y ya no ocurren más, sincrónicamente, como verbos léxicos.

Por último, a pesar de que solo se ha elegido un grupo reducido de lenguas, no parece haber un factor geográfico en la ocurrencia de SD en una lengua. Véase el Mapa 1 donde los SD aparecen en lenguas de las tierras bajas al este de los Andes como el jarawara en las márgenes del Purús y el wanano en el Vaupés. No obstante, respecto a las andinas, parece haber una resistencia y evolución lenta de los SD en el aimara y en el jaqaru, mientras que en el quechua y en el chipaya, los SD son más susceptibles de ser fosilizados y reanalizados o simplemente llegan a ser obsoletos. Ciertamente, llama la atención que tanto las lenguas aimaraicas como las lenguas pano peruanas mantengan todavía sus SD a pesar de la influencia de la lengua dominante, el español. Cabe preguntarse, por cierto, 
si las lenguas pano destacan más la manera que la trayectoria como lo hace el aimara. Siguiendo a Slobin (2004: 251), como hipótesis preliminar, las lenguas aimaraicas y pano deberían tener en pleno uso más verbos de manera que las lenguas con SD limitados y nulos. Esperamos estimular trabajos posteriores en tal sentido.

\section{Referencias}

Adelaar, Willem (1987). Morfología del quechua de Pacaraos. Lima: Universidad Nacional Mayor de San Marcos.

Adelaar, Willem (2004). The languages of the Andes. New York: Cambridge University Press.

Adelaar, Willem (2006). The vicissitudes of directional affixes in Tarma (Northern Junín) Quechua. In Grażyna J. Rowicka; Eithne B. Carlin (eds.), What's in a verb? Studies in the verbal morphology of the languages of the Americas, pp. 121-141. Utrecht: LOT.

Adelaar, Willem (2010). Trayectoria histórica de la familia lingüística quechua y sus relaciones con la familia lingüística aimara. Boletín de Arqueología PUCP 14: 239-254.

Adelaar, Willem (2012). Modeling convergence: Towards a reconstruction of the history of Quechuan-Aymaran interaction. Lingua 122(5): 461-469.

Dos Anjos, Zoraide (2011). Fonologia e gramática Katukina-Kanamari. Utrecht: LOT.

Apontes, Selmo Azevedo (2015). Descrição gramatical do Oro Waram, variante Wari' norte (pakaa nova, Txapakura): fonologia, morfologia e sintaxe (Tese de Doutorado em Linguística). Belo Horizonte: Faculdade de Letras da Universidade Federal de Minas Gerais.

Belleza Castro, Neli (1995). Vocabulario jacaru-castellano, castellano-jacaru. Cuzco: Centro de Estudios Regionales Andinos Bartolomé de las Casas.

Bertonio, Ludovico (1612). Arte de la lengua aymara, con vna silva de phrases de la misma lengua y su declaracion en Romance. Juli, Chucuyto: Francisco del Canto.

Bertonio, Ludovico (1879 [1612]). Vocabulario de la lengua aymara. Leipzig: B. G. Teubner.

Cândido, Gláucia Vieira (2004). Descrição morfossintática da lingua Shanenawa (Pano) (Tese de Doutorado em Linguística). Campinas: Instituto de Estudos da Linguagem, Universidade Estadual de Campinas.

Cerrón-Palomino, Rodolfo (2006). El chipaya o la lengua de los hombres del agua. Lima: Pontificia Universidad Católica del Perú.

Cerrón-Palomino, Rodolfo (2008). Quechumara. Estructuras paralelas del quechua y del aimara. La Paz: Plural Editores.

Cerrón-Palomino, Rodolfo (2010). Contactos y desplazamientos lingüísticos en los Andes centro-sureños: el puquina, el aimara y el quechua. Boletín de Arqueología PUCP 14: 255-282.

Chen, Liang; Guo, Jiansheng (2009). Motion events in Chinese novels: Evidence for an equipollently-framed language. Journal of Pragmatics 41(9): 1749-1766. https://doi.org/10.1016/j.pragma.2008.10.015 


\section{CAJAVILCA VERAMENDI \& CAJAS ASCANOA - REPENSANDO LOS...}

Coler, Matt (2014). A grammar of Muylaq’Aymara. Leiden: Brill.

Croft, William; Barðdal, Jóhanna; Hollmann, Willem; Sotirova, Violeta; Taoka, Chiaki (2010). Revising Talmy’s Typological Classification of Complex Event Constructions. In Boas, Hans C. (ed.), Contrastive Studies in Construction Grammar, pp. 201-235. Amsterdam: John Benjamins Publishing Company.

Dixon, R. M. W. (2004). The Jarawara language of Southern Amazonia. New York: Oxford University Press.

Duff-Tripp, Martha (1997). Gramática del idioma yanesha' (amuesha). Lima: siL. https://www.sil.org/system/ files/reapdata/15/10/76/151076034033358122698909108572274428428/slp43.pdf

Eakin, Lucille (1991). Lecciones para el aprendizaje del idioma yaminahua. Yarinacocha: SIL. https://www.sil.org/system/files/reapdata/14/76/64/147664640441336076360099246953883359406/ dt22.pdf

Emlen, Nicholas Q. (2017). Perspectives on the Quechua-Aymara contact relationship and the lexicon and phonology of Pre-Proto-Aymara. International Journal of American Linguistics 83(2): 307-340.

https://doi.org/10.1086/689911

Faust, Norma; Loos, Eugene E. (2002). Gramática del idioma yaminahua. Lima: SIL. https://www.sil.org/system/ files/reapdata/25/40/97/25409718165761403707379795679194848129/slp51.pdf

Fleck, David William (2003). A grammar of Matses (Ph.D. dissertation). Houston: Rice University. https://scholarship.rice.edu/handle/1911/18526

González, Hebe Alicia (2005). A grammar of Tapiete (Tupi-Guarani) (Ph.D. dissertation). Pittsburgh: Faculty of Arts and Sciences, University of Pittsburgh.

http://d-scholarship.pitt.edu/8444/

González Holguín, Diego (1842 [1607]). Gramática y arte nueva de la lengua general de todo el Peru, llamada lengua qquichua o lengua del Inca. Lima: Francisco del Canto.

González Holguín, Diego (1608). Vocabulario de la lengua general del Perú llamada qquichua o lengua del Inca. Lima: Francisco del Canto.

Gonzalo Segura, Roger R. (2011). La derivación verbal en el aimara de Pomata (Tesis de maestría en Lingüística). Lima: Pontificia Universidad Católica del Perú.

Guillaume, Antoine (2008). A grammar of Cavineña. Berlin: Mouton de Gruyter. https://doi.org/10.1515/9783110211771

Hardman, Martha J. (2000). Jaqaru. München: LINCOM Europa.

Hardman, Martha J. (2001). Aymara. München: LINCOM Europa.

Huayhua Pari, Felipe (2001). Gramática descriptiva de la lengua aimara. Lima: Instituto de Reafirmación de los Pueblos Aimaras, Quechuas y Amazonenses.

Huayhua Pari, Felipe (2009). Diccionario bilingüe polilectal: aimara-castellano, castellano-aimara. Lima: Fondo Editorial UNMSM.

Itier, César (1997). Parlons Quechua: La langue du Cuzco. París: L’Harmattan. 
Kaxinawá, Joaquim Paulo de Lima (2014). Uma gramática da língua Hãtxa Kuĩ. (Tese de doutorado em linguística). Brasília: Instituto de Letras da Universidade de Brasília.

Kindberg, Lee (1980). Diccionario asháninca. Yarinacocha: sIL. https://www.sil.org/system/files/ reapdata/15/05/87/150587103864951424705632321744367293106/dt19.pdf

Lord, Mary Ann (2016). Some features of Yora grammar. Lima: siL. https://www.sil.org/system/files/ reapdata/73/47/24/7347241533305526828888003701777917822/MTS_Some_features_Yora grammar 2016.pdf

Loriot, James; Lauriault, Erwin; Day, Dwight (1993). Diccionario shipibo-castellano. Lima: SIL. https://www.sil.org/system/files/reapdata/28/10/70/28107082976791018432371168218236399036/ slp31.pdf

Marcapaillo Achu, Claudio (2009). Gramática con referencias del aymara del sur. La Paz: IEB/UMSA Asdi/ TB-BRC.

Mihas, Elena (2010). Essentials of Ashéninka Perené grammar (Ph.D. dissertation). Milwaukee: University of Wisconsin-Milwaukee.

http://www.etnolinguistica.org/tese:mihas-2010

Olawsky, Knut J. (2006). A grammar of Urarina. Berlin: Mouton de Gruyter. https://doi.org/10.1515/9783110892932

Payne, David L. (1980). Diccionario ashéninca-castellano. Lima: siL. https://www.sil.org/system/files/ reapdata/27/59/65/27596502782406212904632085133341587136/dt18.pdf

Payne, Thomas E. (1997). Describing Morphosyntax: A guide for field linguists. New York: Cambridge University Press.

Seki, Lucy (2000). Gramática do Kamaiurá: língua Tupi-Guaraní do Alto Xingu. Campinas: Editora da UNICAmP.

Slobin, Dan I. (2004). The many ways to search for a frog. In Sven Strömqvist; Ludo Verhoeven (eds.), Relating events in narrative: Typological and contextual perspectives, pp. 219-257. Mahwah: Lawrence Erlbaum Associates.

Snell, Betty A. (2011). Diccionario matsigenka - castellano. Lima: SIL. https://www.sil.org/system/files/ reapdata/18/56/85/18568503648705946088000241499027872639/mcbDIC web.pdf

Stenzel, Kristine Sue (2004). A reference grammar of Wanano (Ph.D. dissertation). Boulder: Department of Linguistics, University of Colorado.

http://etnolinguistica.wdfiles.com/local--files/tese:stenzel-2004/stenzel_2004_wanano.pdf

Talmy, Leonard (2007). Lexical typologies. In Timothy Shopen (ed.), Language typology and syntactic description. Grammatical categories and the lexicon, pp. 66-168. Second edition. New York: Cambridge University Press.

Tanghe, Sanne (2016). Marcadores derivados de verbos de movimiento. Berlín: De Gruyter. https://doi.org/10.1515/9783110489019

Thiesen, Wesley (1996). Gramática del idioma bora. Yarinacocha: siL. https://www.sil.org/system/files/ reapdata/93/62/62/93626202298399583892707163524971882511/slp38.pdf

LIAMES, Campinas, SP, v. 20, 1-32, e020009, 2020 


\section{CAJAVILCA VERAMENDI \& CAJAS ASCANOA - REPENSANDO LOS...}

Thiesen, Wesley; Thiesen, Eva (1998). Diccionario bora-castellano castellano-bora. Lima: SIL. https://www.sil.org/system/files/reapdata/35/51/46/35514688022326444724729301491753893052/ slp46.pdf

Thiesen, Wesley; Weber, David (2012). A grammar of Bora with special attention to tone. Dallas: SIL International.

Weber, David J. (1996). Una gramática del quechua del Huallaga (Huánuco). Lima: SIL. https:/www.sil.org/system/files/reapdata/80/56/14/80561464172301094114269564920720909838/ slp40.pdf

Weber, David John; Cayco Zambrano, Félix; Cayco Villar, Teodoro; Ballena Dávila, Marlene (1998). Rimaycuna. Quechua de Huánuco. Lima: Instituto Lingüístico de Verano.

Zariquiey, Roberto (2011). A grammar of Kashibo-Kakataibo (Ph.D. disertation). Bundoora: Research Centre for Linguistic Typology, La Trobe University.

http://hdl.handle.net/1959.9/524397

Zariquiey, Roberto (2015). Bosquejo gramatical de la lengua iskonawa. Boston: Latinoamericana Editores/ CELACP.

https://sites.tufts.edu/iskonawa/files/2015/11/Bosquejo-gramatical-del-Iskonawa-completo.pdf

Zheng, Mingyu; Goldin-Meadow, Susan (2002). Thought before language: How deaf and hearing children express motion events across cultures. Cognition 85(2): 145-175.

$\underline{10.1016 / \mathrm{s} 0010-0277(02) 00105-1}$ 


\section{Abreviaciones}

1, 2, 3 primera, segunda, tercera persona

$1 \mathrm{EXC} \quad$ primera persona no singular exclusiva

A

ABS sujeto de verbo transitivo

ACT.NML nominalizador de actividad

ADJZR

adjetivizador

ADV

marca cláusula adverbial

ADVZR

adverbializador

ANA

pronombre anafórico

AOR

aoristo

APL

aplicativo

APL.INT

aplicativo de intención

ASER

asertivo

AUM

aumentativo

AUX

auxiliar

CAU

causativo

CON

aspecto continuo

DEC

modo declarativo

DEP

cláusula dependiente

DERO

derogativo

DIM

diminutivo

DIR

direccional

DIS

distributivo

DIST

distal

DUR

durativo

ENF

enfático

EP

epéntesis

EVI

evidencial

$\mathrm{f}$

femenino

FOC

focalizador

GEN

genitivo

HAB

habitual

IDEO

ideófono

INT

verbo intransitivo

IPAS

pasado inmediato

IRR

modalidad irrealis

LOC

locativo

$\mathrm{m}$

masculino

MSP

modo segundo plano

$\mathrm{nm}$

no masculino

NML

nominalizador

NSG

no singular

$\mathrm{O}$

objeto 
CAJAVILCA VERAMENDI \& CAJAS ASCANOA - REPENSANDO LOS...

PAS

PL

tiempo pasado

POS

PRF

plural

PRO

posesivo

perfectivo

PROP

RDP

progresivo

propósito

REAL

reduplicación

REG

modalidad realis

REM

regresivo

pasado remoto

$\mathrm{S}$

SD

SG

sujeto de verbo intransitivo

sufijo(s) direccional(es)

singular

SW.REF

REAL

switch referencia

REG

modalidad realis

REM

regresivo

pasado remoto

$\mathrm{S}$ sujeto de verbo intransitivo

SD

SG sufijo(s) direccional(es)

SW.REF

singular

TR

switch referencia

VBL verbo transitivo

VM verbalizador verbo(s) de movimiento

Recebido: 7/7/2020

Versão revista e corrigida: 19/8/2020

Aceito: 26/8/2020 